\title{
A Discrete-Time Decoupled Current Control Scheme Applied to VSC-Based Three-Phase Three-Line Systems
}

\author{
Hui Wang, Qingmin Li, Guangzhu Wang, and Xingguo Tan \\ School of Electrical Engineering, Shandong University, 73 Jing Shi Road, Shandong, Jinan 250061, China \\ Correspondence should be addressed to Qingmin Li, lqmeee@sdu.edu.cn
}

Received 14 February 2011; Revised 2 June 2011; Accepted 5 June 2011

Academic Editor: C. M. Liaw

Copyright () 2011 Hui Wang et al. This is an open access article distributed under the Creative Commons Attribution License, which permits unrestricted use, distribution, and reproduction in any medium, provided the original work is properly cited.

\begin{abstract}
Accurate current control of the voltage source converters (VSCs) is one of the key research subjects in modern power electronics. To achieve a preferable solution to current coupling effect in the VSC-based three-phase three-line system, a discrete-time decoupled current control strategy is proposed in the paper. With integration of the $\alpha-\beta$ transform and two independent current controllers, the proposed methodology can effectively implement decoupled control of the three-phase currents, which can thereby eliminate the impact from the neutral-point voltage especially under asymmetrical loading conditions. Control performance under digital realization was characterized with extensive tests on a shunt active power filter (SAPF) platform. Both the simulative and experimental results have demonstrated that the SAPF could function well and thereby verified the feasibility and effectiveness of the proposed current control methodology.
\end{abstract}

\section{Introduction}

Based on fully controlled power semiconductors, voltage source converters (VSCs), such as DC-DC, DC-AC, and AC-DC converters, are being more widely used than current source converters (CSCs), as the DC side capacitor used for energy storage in a VSC is much superior to an inductor in a CSC in terms of weight, cost, and efficiency, especially suitable for the nowadays switching semiconductors. For concrete applications with VSCs, such as active power filters (APF), PWM rectifiers, power factor correction (PFC), HVDC light and grid-connected inverters, an accurate current control methodology with preferable dynamic performance is indispensible and critical [1-7]. Current control is normally used for the inner closed loop in a VSC-based system, in which PWM signals are directly generated to track the current reference accurately as well as ameliorate controllability and dynamic response of the system.

For a three-phase four-line circuitry of a VSC, the current control strategy makes no difference at all from that for a single-phase system since the phase currents are independent of each other in the circuitry. However, in a three-phase three-line system, the three-phase currents are interactional and electromagnetically coupled. As a result, only two circuit equations are independent accordingly. In addition, the neutral point voltage of the three-line circuitry will also affect the behavior of current tracking control in the VSC, especially when the three-phase voltages or loads are not symmetrically presented. Hence, it is a pending issue to be properly tackled of the current control strategy in a VSCbased three-phase three-line circuitry.

Most of the nowadays current control strategies are based on the $\mathrm{d}-\mathrm{q}$ synchronous rotating frame as to decouple the active currents and the reactive currents in a three-phase VSC system [7-12], in which the physical concepts of the adopted variables are unique and clear; however, the instant value of the angular power frequency $\omega$ and the output inductance of the VSC should be known in advance. Also, the sensible impact of the neutral point voltage was not incorporated [ 9 , $10,12]$. References $[13,14]$ advised using an $\alpha-\beta$ stationary frame to transform the mathematical model of an APF, and the VSC topology was designed in the $\alpha-\beta$ stationary frame so as to achieve current decoupling, which did facilitate the control strategy but the corresponding hardware design became much more complicated than before. 
To cope with the above-mentioned issues, based on a general mathematical model of the three-phase three-line VSC system, the impact of the neutral point voltage on current control scheme was fully elucidated in this paper. Further, a discrete-time mathematical model in the $\alpha-\beta$ coordinate system was established through orthogonal transform, with a view to developing a decoupled current control strategy as to eliminate the impact of the neutral point voltage and finally achieve decoupling of the three-phase currents. Simulation and experimental results on an APF prototype under nonlinear loading conditions were also presented for verification purpose.

\section{Impact of Current Coupling in a Three-Line VSC System}

For a typical VSC configuration in the three-line system as shown in Figure 1, several assumptions are made as follows in establishing a mathematical model: (1) the sources and loads are in $\mathrm{Y}$ connection ( $\Delta$ connection can be transferred into Y connection); (2) the three-line inductance is ignored due to its very small value and little effect; (3) the three-line resistances $R_{s}$ and the output Inductor $L_{f}$ of the VSC unit are symmetrical; (4) the mathematical model of the VSC unit is described in the continuous-time system for convenience.

Given asymmetrical sources or loads in the three-phase system, the phase voltages $u_{S a}, u_{S b}$, and $u_{S c}$ can be expressed as follows:

$$
u_{S a}+u_{S b}+u_{S c}=\Delta u \neq 0 .
$$

If the sources and loads are symmetrical in the threephase system, then $u_{S a}+u_{S b}+u_{S c}=\Delta u=0$ will be fulfilled. For the three-line voltages $u_{a b}, u_{b c}$, and $u_{c a}$ in the AC side, one gets

$$
u_{a b}+u_{b c}+u_{c a} \equiv 0 .
$$

Based on Kirchhoff's Voltage Law, the circuit equation of phase A is governed by

$$
L_{f} \frac{d i_{S a}}{d t}=u_{S a}-R_{S} i_{S a}-u_{a N}-u_{N 0} .
$$

If the switching states of $S_{1}, S_{2}$, and $S_{3}$ are expressed by $p_{a}$, $p_{b}$, and $p_{c}$, then $\left(p_{a}, p_{b}, p_{c}\right) \in(0,1)$, where logic 1 represents that the upper-leg switch is turned on while the lower-leg switch is turned off. Similarly, logic 0 represents the lowerleg switch is turned on while the upper-leg switch is turned off. If $S_{1}$ is turned on and $S_{2}$ is turned off, then $p_{a}=1$ and $u_{a N}=u_{\mathrm{DC}}$. If $S_{2}$ is turned on and $S_{1}$ is turned off, then $p_{a}=0$ and $u_{a N}=0$. Hence, we get $u_{a N}=u_{\mathrm{DC}} p_{a}$ and (3) can be changed to

$$
L_{f} \frac{d i_{S a}}{d t}=u_{S a}-R_{S} i_{S a}-u_{\mathrm{DC}} p_{a}-u_{N 0} .
$$

In the same way, the governing equations of phase $\mathrm{B}$ and phase $\mathrm{C}$ are obtained as follows:

$$
\begin{aligned}
& L_{f} \frac{d i_{S b}}{d t}=u_{S b}-R_{S} i_{S b}-u_{\mathrm{DC}} p_{b}-u_{N 0}, \\
& L_{f} \frac{d i_{S c}}{d t}=u_{S c}-R_{S} i_{S c}-u_{\mathrm{DC}} p_{c}-u_{N 0},
\end{aligned}
$$

where $i_{S a}, i_{S b}$, and $i_{S c}$ denote the three-line currents, $u_{a N}, u_{b N}$, and $u_{c N}$ represent the phase voltages relative to point $N, u_{\mathrm{DC}}$ expresses the DC side voltage and $u_{N 0}$ denotes the voltage difference between point $N$ and the neutral point.

Obviously, the three-line currents will meet

$$
i_{S a}+i_{S b}+i_{S c}=0 .
$$

Based on (4) to (7), the following relationship can be derived:

$$
\begin{aligned}
\left(u_{S a}-\right. & \left.R_{S} i_{S a}-u_{\mathrm{DC}} p_{a}-u_{N 0}\right)+\left(u_{S b}-R_{S} i_{S b}-u_{\mathrm{DC}} p_{b}-u_{N 0}\right) \\
& +\left(u_{S c}-R_{S} i_{S c}-u_{\mathrm{DC}} p_{c}-u_{N 0}\right)=0 .
\end{aligned}
$$

Further, we can get

$$
u_{N 0}=\frac{1}{3} \Delta u-\frac{u_{\mathrm{DC}}}{3}\left(p_{a}+p_{b}+p_{c}\right) .
$$

If (9) is substituted into (4) to (6), the mathematical model of the VSC unit can be obtained when the sources or loads are in asymmetrical conditions:

$$
\begin{aligned}
& L_{f} \frac{d i_{S a}}{d t}=u_{S a}-R_{S} i_{S a}-u_{C a}-\frac{1}{3} \Delta u, \\
& L_{f} \frac{d i_{S b}}{d t}=u_{S b}-R_{S} i_{S b}-u_{C b}-\frac{1}{3} \Delta u, \\
& L_{f} \frac{d i_{S c}}{d t}=u_{S c}-R_{S} i_{S c}-u_{C c}-\frac{1}{3} \Delta u,
\end{aligned}
$$

where

$$
\begin{aligned}
& u_{C a}=\frac{u_{\mathrm{DC}}\left(2 p_{a}-p_{b}-p_{c}\right)}{3}, \\
& u_{C b}=\frac{u_{\mathrm{DC}}\left(-p_{a}+2 p_{b}-p_{c}\right)}{3}, \\
& u_{C c}=\frac{u_{\mathrm{DC}}\left(-p_{a}-p_{b}+2 p_{c}\right)}{3} .
\end{aligned}
$$

For the symmetrical conditions of the sources or loads in the three-phase system, $u_{S a}+u_{S b}+u_{S c}=\Delta u=0$ will be met, which directly results in the corresponding mathematical model of the VSC shown below:

$$
\begin{aligned}
& L_{f} \frac{d i_{S a}}{d t}=u_{S a}-R_{S} i_{S a}-u_{C a}, \\
& L_{f} \frac{d i_{S b}}{d t}=u_{S b}-R_{S} i_{S b}-u_{C b}, \\
& L_{f} \frac{d i_{S c}}{d t}=u_{S c}-R_{S} i_{S c}-u_{C c} .
\end{aligned}
$$

Only two governing equations are outstandingly independent since the summation of the three-phase currents always is equal to zero as shown in (7). With regard to the asymmetrical system, (10) shows that the neutral point voltage will impose direct impact on the tracking control performance of output currents in the VSC system. 


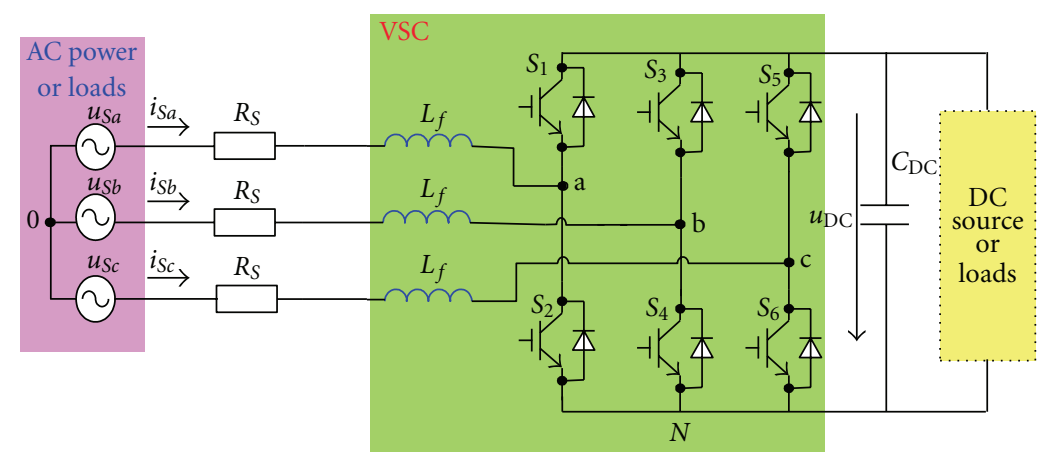

FIGURE 1: Typical configuration of a three-phase VSC.

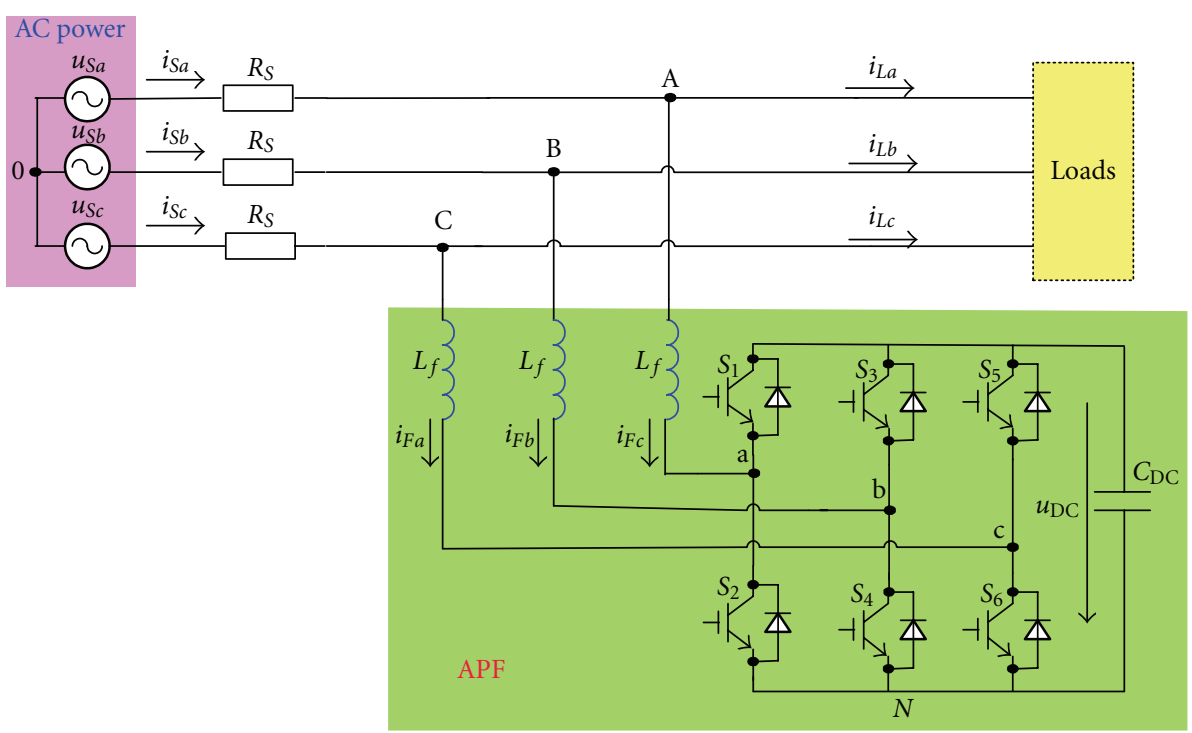

FIgure 2: Typical configuration of a shunt APF topology.

For an example shown in Figure 2, where a VSC unit is utilised in a shunt APF topology with nonlinear loads, simulations are carried out with the PSIM software. The source frequency of the APF system is $50 \mathrm{~Hz}$ and the source voltage is $220 \mathrm{~V}$ (RMS). The nonlinear load is represented by a three-phase rectifier in a symmetrical system, and the three-phase rectifier connected with an asymmetrical RLC circuitry denotes the loads within the asymmetrical system. Referential command currents are calculated by the instantaneous reactive power theory, while the APF output currents are controlled by a classical PID controller. Without considering the affection of current coupling under the symmetrical or asymmetrical condition, Figure 3 shows the load and source currents in phase A after compensation of the shunt APF, while Figure 4 typically shows that under asymmetrical conditions including source or loads asymmetry. By comparison of the simulated results it can be seen that the current tracking error in the asymmetric system is much larger than that in the symmetric system. Hence, proper measures must be taken to counteract the current tracking errors that resulted from current coupling as well as the neutral point voltage.

\section{Discrete-Time Mathematical Model of the Three-Phase Three-Line VSC in $\alpha-\beta$ Domain}

The discrete-time expression of the mathematical model of a three-phase three-line VSC can be derived from (10) as follows:

$$
\begin{aligned}
& L_{f} \frac{i_{S a}(k+1)-i_{S a}(k)}{T}=u_{S a}(k)-R_{S} i_{S a}(k)-u_{C a}(k)-\frac{1}{3} \Delta u(k), \\
& L_{f} \frac{i_{S b}(k+1)-i_{S b}(k)}{T}=u_{S b}(k)-R_{S} i_{S b}(k)-u_{C b}(k)-\frac{1}{3} \Delta u(k), \\
& L_{f} \frac{i_{S c}(k+1)-i_{S c}(k)}{T}=u_{S c}(k)-R_{S} i_{S c}(k)-u_{C c}(k)-\frac{1}{3} \Delta u(k),
\end{aligned}
$$

where $T$ is the sampling interval, $k=0,1, \ldots, n$. 

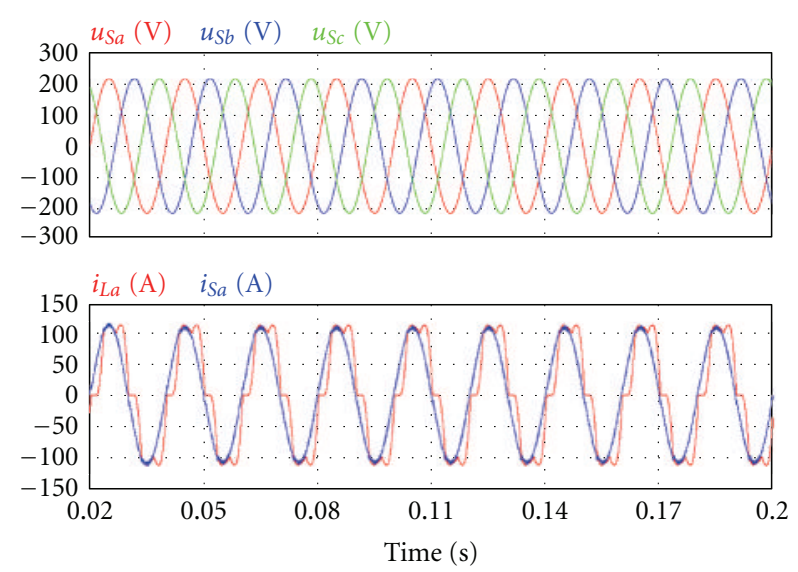

Figure 3: Current waveforms of a shunt APF in the symmetrical system.

Based on $\alpha-\beta$ transform of the instantaneous reactive power theory, (13) can be transformed into the $\alpha$ - $\beta$ domain through the orthogonal transform matrix $\mathbf{C}$, which transforms the three-phase system to a two-phase system, as shown in (17):

$$
\begin{gathered}
\mathbf{C}=\sqrt{\frac{2}{3}}\left[\begin{array}{ccc}
1 & -\frac{1}{2} & -\frac{1}{2} \\
0 & \frac{\sqrt{3}}{2} & -\frac{\sqrt{3}}{2}
\end{array}\right], \\
{\left[\begin{array}{l}
u_{S \alpha}(k) \\
u_{S \beta}(k)
\end{array}\right]=\mathrm{C}\left[\begin{array}{l}
u_{S a}(k) \\
u_{S b}(k) \\
u_{S c}(k)
\end{array}\right],} \\
{\left[\begin{array}{l}
i_{S \alpha}(k) \\
i_{S \beta}(k)
\end{array}\right]=\mathrm{C}\left[\begin{array}{l}
i_{S a}(k) \\
i_{S b}(k) \\
i_{S c}(k)
\end{array}\right],} \\
\left.u_{C \beta}(k)\right]=\mathrm{C}\left[\begin{array}{l}
u_{C \alpha}(k)-\frac{1}{3} \Delta u(k) \\
u_{C b}(k)-\frac{1}{3} \Delta u(k) \\
u_{C c}(k)-\frac{1}{3} \Delta u(k)
\end{array}\right]=\mathrm{C}\left[\begin{array}{l}
u_{C a}(k) \\
u_{C b}(k) \\
u_{C c}(k)
\end{array}\right] .
\end{gathered}
$$

The expressions in (17) clearly indicate that the items associated with the neutral point voltage have disappeared in the $\alpha-\beta$ domain, which means the same current tracking control behavior of an asymmetrical system as that of a symmetrical system. Therefore, if the current control scheme of the three-line VSC is implemented directly in the $\alpha-\beta$ domain, it would be unnecessary to consider the impact any more from the neutral point voltage, and only two controllers are thereby required. As a result, there comes the

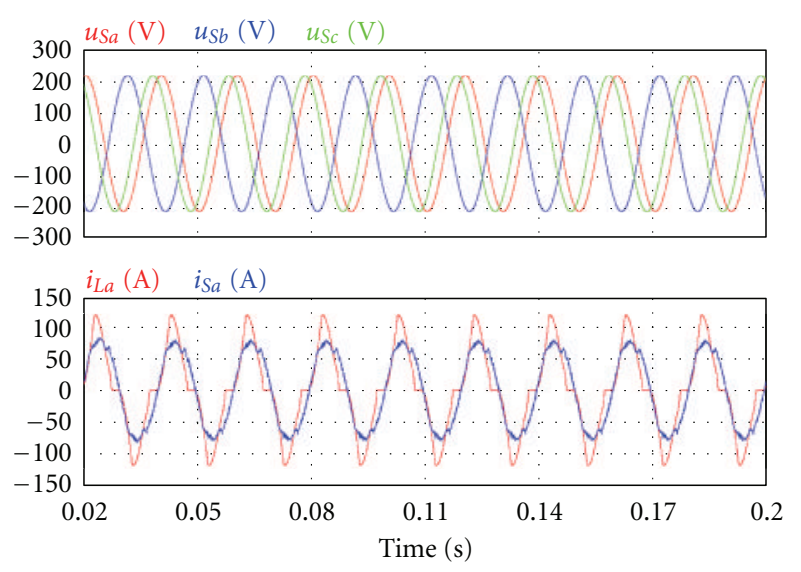

(a) Asymmetrical source system

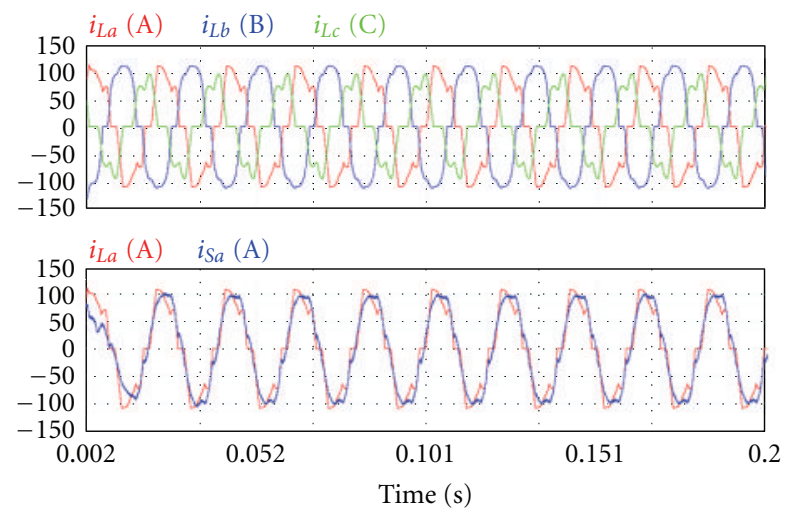

(b) Asymmetrical loads system

FIGURE 4: Current waveforms of a shunt APF in the asymmetrical system.

discrete-time mathematical model of the three-phase threeline VSC in the $\alpha-\beta$ domain, based on which decoupled current control will be achieved accordingly:

$$
\begin{aligned}
& L_{f} \frac{i_{S \alpha}(k+1)-i_{S \alpha}(k)}{T}=u_{S \alpha}(k)-R_{S} i_{S \alpha}(k)-u_{C \alpha}(k), \\
& L_{f} \frac{i_{S \beta}(k+1)-i_{S \beta}(k)}{T}=u_{S \beta}(k)-R_{S} i_{S \beta}(k)-u_{C \beta}(k) .
\end{aligned}
$$

\section{Implementation of the Decoupled Current Control Scheme}

Here a classical PID controller is combined with the decoupled current control scheme of the VSC in the $\alpha-\beta$ domain, the diagram of which is shown in Figure 5. The input of the controller is defined as

$$
e_{j}(k)=i_{S j}^{*}(k)-i_{S j}(k),
$$

where $j=\alpha, \beta$ and $i_{S j}^{*}$ denotes the referential command currents of the VSC in the $\alpha-\beta$ domain. The current control loop is realized using a DSP hardware controller, in which 
the current references are calculated and given by the instantaneous reactive power theory. The output currents of the VSC are sampled by the DSP element as to be the current feedback.

Since the sampling interval $T$ is small, then $i_{S j}^{*}(k+1) \approx$ $i_{S j}^{*}(k)$. From (18) and (19), one can get

$$
\begin{aligned}
e_{j}(k+1)-e_{j}(k) & =-i_{S j}(k+1)+i_{S j}(k) \\
& =-\frac{T}{L_{f}}\left(u_{S j}(k)-R_{S} i_{S j}(k)-u_{C j}(k)\right) .
\end{aligned}
$$

The incremental form of the discrete-time PID algorithm is applied, namely,

$$
\begin{aligned}
\Delta e_{j}(k+1)= & e_{j}(k+1)-e_{j}(k) \\
= & k_{P}\left(e_{j}(k+1)-e_{j}(k)+\frac{T}{T_{I}} e_{j}(k+1)\right. \\
& \left.\quad+\frac{T_{D}}{T}\left(e_{j}(k+1)-2 e_{j}(k)+e_{j}(k-1)\right)\right),
\end{aligned}
$$

where $k_{P}, T_{I}$ and $T_{D}$ represent the PID controller parameters. Combination of (20) and (21) gives the expression of the prosed control strategy:

$$
u_{C j}(k)=u_{S j}(k)-R_{S} i_{S j}(k)+\frac{L_{f}}{T} \Delta e_{j}(k) .
$$

Firstly, the controller output is calculated according to (22). Then, based on the relationship between the output and the switching logic, the states of the switches $S_{1}, S_{2}$, and $S_{3}$ can be determined. Finally, the controlling signals of the three-phase PWM are generated accordingly.

With substitution of (11), (17) corresponding to the control strategy can be changed into

$$
\begin{aligned}
{\left[\begin{array}{l}
u_{C \alpha}(k) \\
u_{C \beta}(k)
\end{array}\right] } & =\mathrm{C}\left[\begin{array}{l}
u_{C a}(k) \\
u_{C b}(k) \\
u_{C c}(k)
\end{array}\right] \\
& =\left[\begin{array}{c}
\frac{\sqrt{3}}{2} u_{C a}(k) \\
\frac{\sqrt{2}}{2}\left(u_{C a}(k)+2 u_{C b}(k)\right)
\end{array}\right] \\
& =\sqrt{\frac{1}{6}}\left[\begin{array}{ccc}
2 & -1 & -1 \\
0 & \sqrt{3} & -\sqrt{3}
\end{array}\right]\left[\begin{array}{c}
p_{a}(k) \\
p_{b}(k) \\
p_{c}(k)
\end{array}\right] u_{\mathrm{DC}}(k) .
\end{aligned}
$$

According to (22) and (23), the following relationship can be obtained.

$$
\begin{aligned}
& \text { If } u_{C \alpha}(k)<0, p_{a}(k)=0 \text {; if } u_{C \alpha}(k)>0, p_{a}(k)=1 . \\
& \text { If } u_{C \beta}(k)<0, p_{b}(k)=0 \text { and } p_{c}(k)=1 \text {; if } u_{C \beta}(k)>0, \\
& p_{b}(k)=1 \text { and } p_{c}(k)=0 .
\end{aligned}
$$

TABLE 1: True value table of three-phase PWM switching signal.

\begin{tabular}{lcccc}
\hline \multicolumn{2}{l}{ Output of the controller } & \multicolumn{3}{c}{ Output of the PWM signals } \\
$u_{C \alpha}$ & $u_{C \beta}$ & $p_{a}$ & $p_{b}$ & $p_{c}$ \\
\hline$<0$ & $<0$ & 0 & 0 & 1 \\
$<0$ & $>0$ & 0 & 1 & 0 \\
$<0$ & 0 & 0 & 1 & 1 \\
$>0$ & 0 & 1 & 0 & 0 \\
$>0$ & $<0$ & 1 & 0 & 1 \\
$>0$ & $>0$ & 1 & 1 & 0 \\
\hline
\end{tabular}

If $u_{C a}(k)<0$ and $u_{C \beta}(k)=0, p_{b}(k)=1$ and $p_{c}(k)=1$; if $u_{C a}(k)>0$ and $u_{C \beta}(k)=0, p_{b}(k)=0$ and $p_{c}(k)=0$.

The true values of the three-phase PWM switching signals are consequently given in Table 1 for the discrete-time decoupled current control methodology.

The switching states in the three legs can be determined by collating the true value table according to the output of the discrete-time controller acquired from (23). The three-phase PWM switching signals will be generated as to subsequently realize decoupled control of the three-current $i_{a}, i_{b}$, and $i_{c}$.

\section{Simulation and Experiment}

Performance verification of the proposed decoupled current control methodology is carried out on a developed VSCbased shunt APF system, as shown in Figure 2.

5.1. Simulation Results. The available program PSIM is adopted to establish simulation models as to verify the effectiveness and validity of the new algorithm proposed above. This simulation topology is the same as the shunt APF system shown in Figure 2, and the nonlinear load is also represented by a three-phase rectifier connected with an asymmetrical RLC circuitry. The whole system is simulated in the discrete-time domain while the sampling frequency is set to $12 \mathrm{kHz}$. The current reference signals to be tracked are acquired by the instantaneous reactive power theory, in which low-pass digital filters (LPFs) of the second-order Butterworth IIR type are incorporated [15]. The circuits for two-phase current controller are established, as well as the logic circuits to implement the decoupled control scheme. Here, the maximum switching frequency is set to $20 \mathrm{kHz}$ in the simulations.

Figure 6 shows the three-phase load currents. The compensated currents of the shunt APF can be acquired by adjusting the parameters of the two PID controllers. As an example, both the supply voltage and current of phase A are given in Figure 7, which indicates that the supply current can be effectively compensated to be in phase with the supply voltage. A transition process as well as a little steady error may exist due to the dynamic characteristics of the lowpass digital filters being adopted; however, they can be easily avoided if the physical compensating operation starts from some instant within the steady status of the digital filters. The 


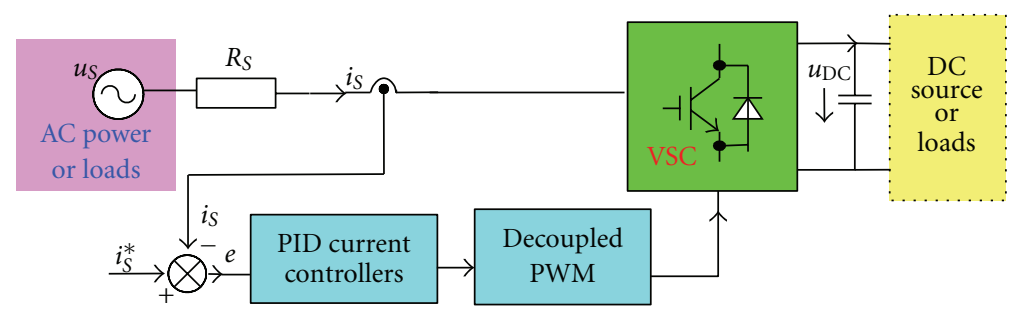

FIgURE 5: Schematic diagram of the proposed current control scheme.

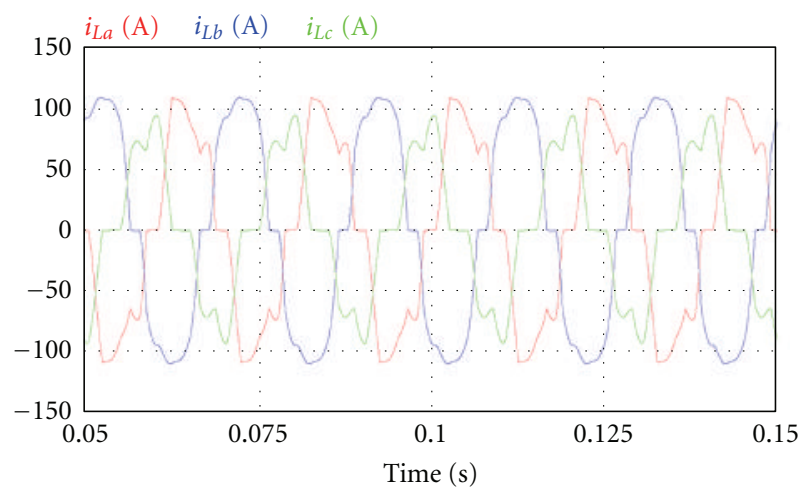

FIgURE 6: The three-phase load currents.

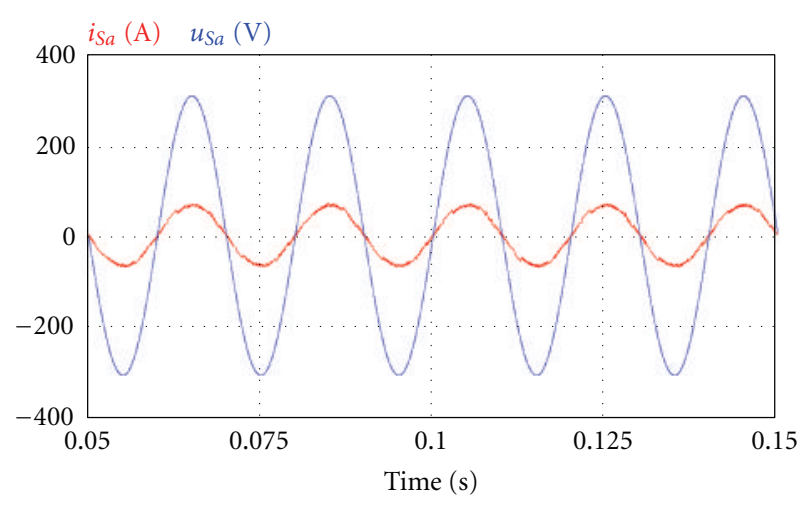

FIGURE 7: The supply voltage and current of phase A.

three-phase PWM signals shown in Figure 8 for decoupled current control can be acquired according to Table 1. It can be seen that the spectrum of phase $\mathrm{A}$ is deferent from that of the other two phases, which is mainly due to the decoupled process being carried out between phase $\mathrm{B}$ and phase $\mathrm{C}$.

5.2. Experimental Results. An experimental platform for the VSC-based shunt APF system has been established, in which the proposed decoupled current control scheme is incorporated. The converter is controlled within a closed loop by a 32-bit $150 \mathrm{MHz}$ DSP element. Figure 9 shows the schematic diagram of the $400 \mathrm{~V}$ shunt APF circuitry for experimental setup. Here the source voltage is in $50 \mathrm{~Hz}$ and rated at $220 \mathrm{~V}$ (RMS). In the experiments, a three-phase
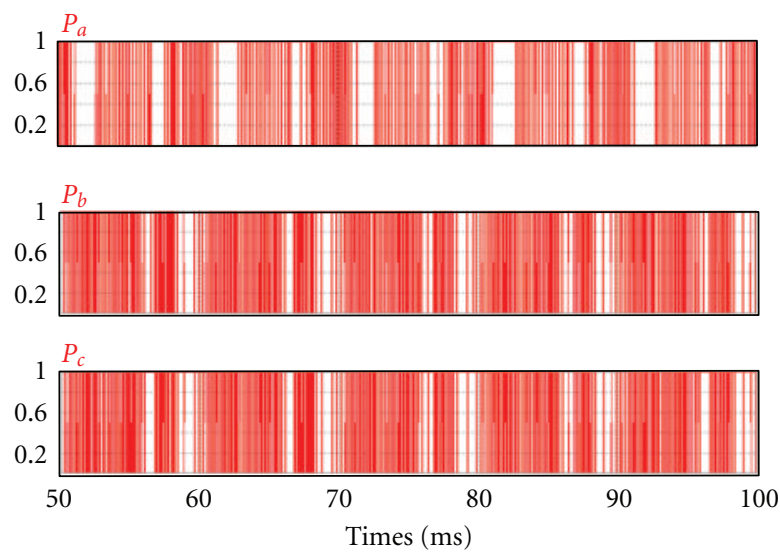

FIgURE 8: The generated three-phase PWM signals.

rectifier being connected with an asymmetrical RLC circuitry is used to act as the loads which are similar to that in the above simulations.

The experimental platform, consisting of a converter and a control circuit, functions well to realize data acquisition, signal driver, generation of the compensated current, and so on. Three HALL voltage sensors as well as six HALL current sensors are used to pick up the three-phase supply voltages, supply currents, and load currents. The detected signals are amplified and isolated by the signal modulating unit before being sent into the DSP module. The most important component of the shunt APF converter is an IGBT-based intelligent power module (IPM). Also, several DC sources are designed with sufficient isolation to output $+5 \mathrm{~V},+3.3 \mathrm{~V}$, and $+1.9 \mathrm{~V}$ for experimental usage. An executive program is written into the DSP module to complete signal sampling, calculation of the harmonic and reactive currents, output current control of the shunt APF and the DC side voltage with a PID controller, and so forth.

All the waveforms are captured with a digital oscilloscope Agilent DOS5034A. In spite of the supply current fed by the current clamp directly into the oscilloscope, the rest waveforms are taken from the entry of the DSP module.

Figure 10 shows the asymmetrical load currents, while Figure 11 shows the three-phase output currents of the shunt APF unit. In Figures 12, 13, and 14, the experimental results for the voltages and currents of phase A, B, and C after compensation are presented, the four waveforms of which in 


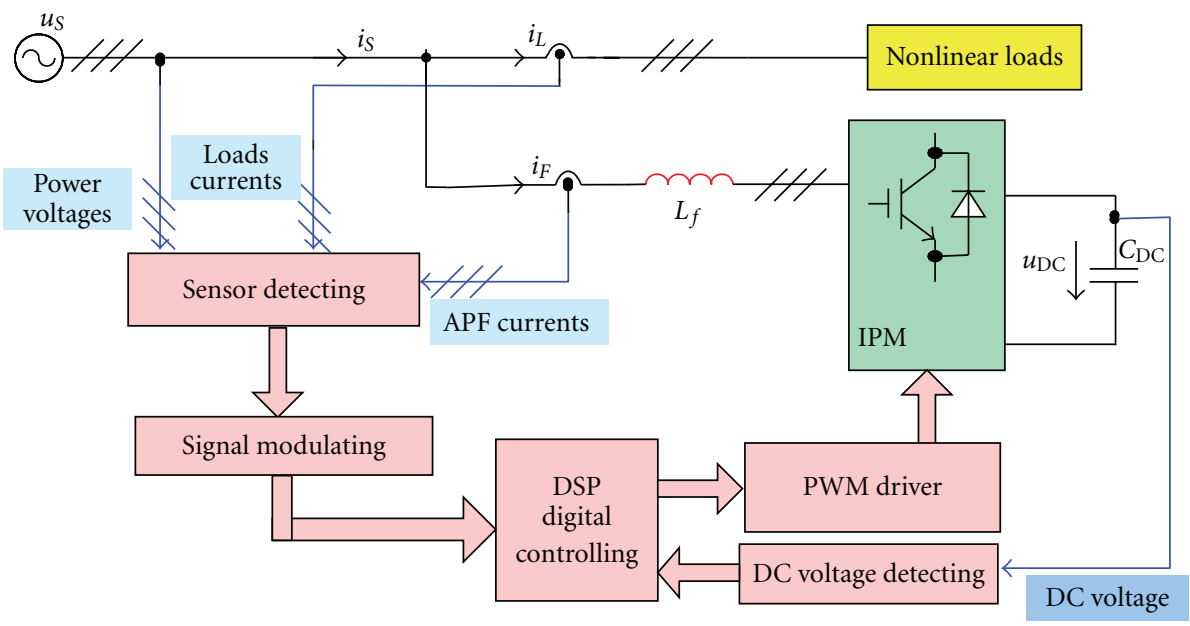

FIgURE 9: Schematic diagram of the VSC-based shunt APF setup for experimental study.

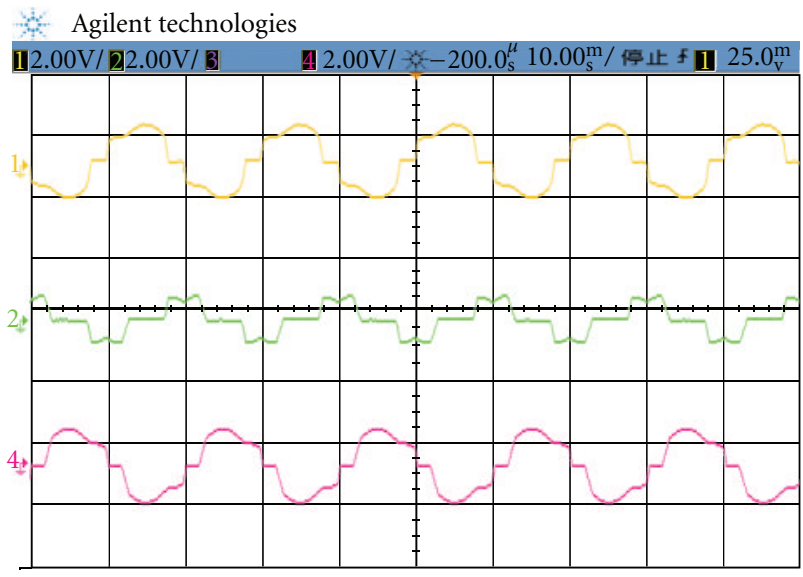

FIgURE 10: The three-phase load currents (10 A/div).

turn from upward to downward denote the supply voltage, the compensation current of the shunt APF, the supply current, and the load current.

Figure 15 shows the measured voltages and currents of phase $\mathrm{C}$ when the shunt APF starts running with a load step, the four waveforms of which in turn denote the supply voltage, the compensation current, the supply current, and the load current.

It can be seen from the experimental waveforms that, with a fast control loop based on the decoupled current control methodology, the supply current will be approximately compensated into a power-frequency sine wave, in which the low-frequency harmonics are significantly reduced. Also, the supply current can be compensated to be exactly in phase with the supply voltage of base-frequency. The experimental studies demonstrate that the new control algorithm proposed in this paper can effectively and correctly realize instantaneous compensation of the harmonics and the reactive power. The decoupled current control algorithm

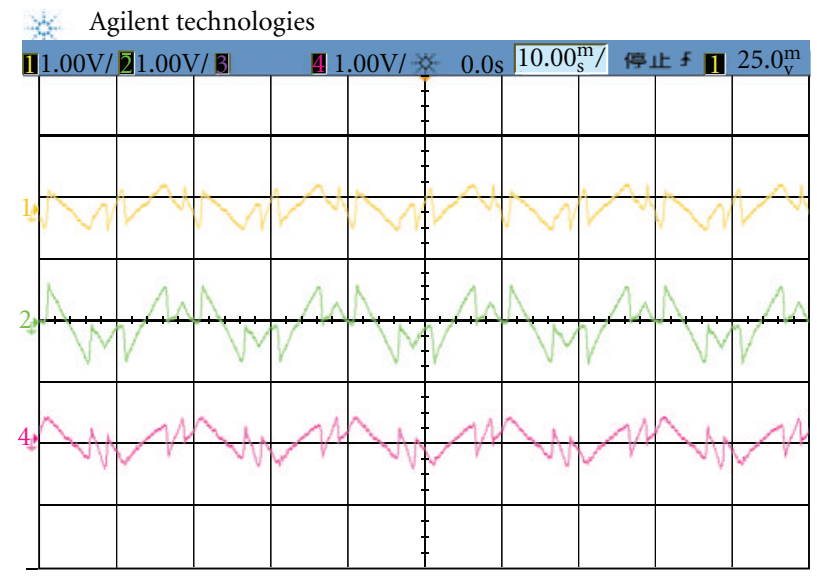

FIGURE 11: The output currents of the shunt APF unit ( $5 \mathrm{~A} /$ div).

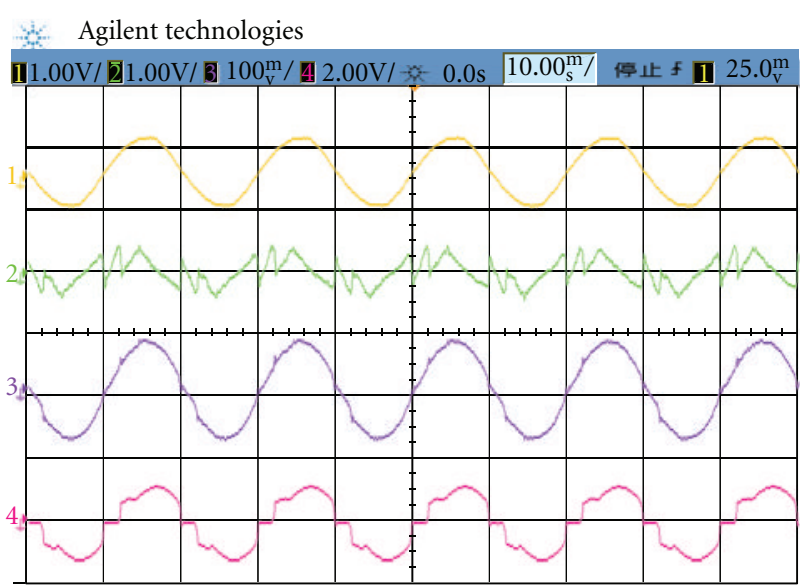

Figure 12: The voltage and currents of phase A ((1) $600 \mathrm{~V} / \mathrm{div},(2)$ $5 \mathrm{~A} / \mathrm{div},(3) 10 \mathrm{~A} / \mathrm{div}$, and (4) $10 \mathrm{~A} / \mathrm{div})$. 


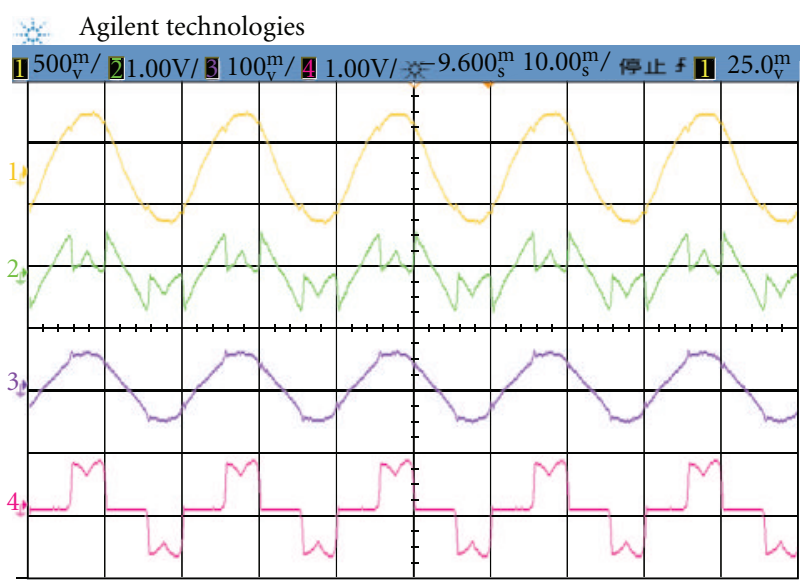

Figure 13: The voltage and currents of phase B ((1) $300 \mathrm{~V} / \mathrm{div},(2)$ $5 \mathrm{~A} / \mathrm{div}$, (3) $10 \mathrm{~A} / \mathrm{div}$, and (4) $5 \mathrm{~A} / \mathrm{div}$ ).

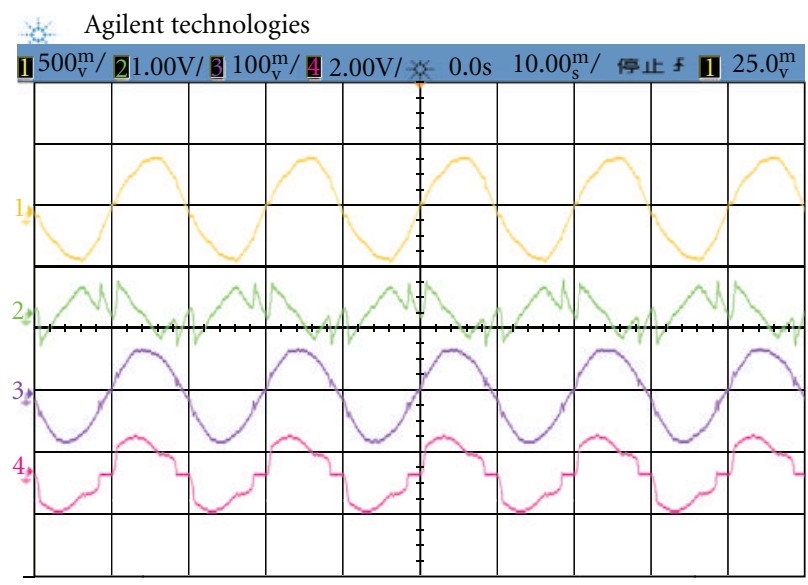

FIgUre 14: The voltage and currents of phase C ((1) 300 V/div, (2) $5 \mathrm{~A} / \mathrm{div}$, (3) $10 \mathrm{~A} / \mathrm{div}$, and (4) $10 \mathrm{~A} / \mathrm{div}$ ).

presents a significant strategy to counteract the impact from either the current coupling or the nonlinear and asymmetrical loading conditions, which also helps to extend the application of VSC-based shunt APF technology in power systems.

\section{Conclusion}

The coupling effect of the three-phase currents in a three-line VSC-based system increases the difficulty of current tracking control. The paper proposed an effective decoupled current control scheme which was verified by both simulative and experimental studies.

Only two governing equations are independent in the mathematical model of a three-phase three-line VSC-based system since the summation of the three-phase currents is always zero. Further, for asymmetrical conditions, the neutral point voltage will directly affect the tracking control behavior of the VSC output currents. Simulations verified

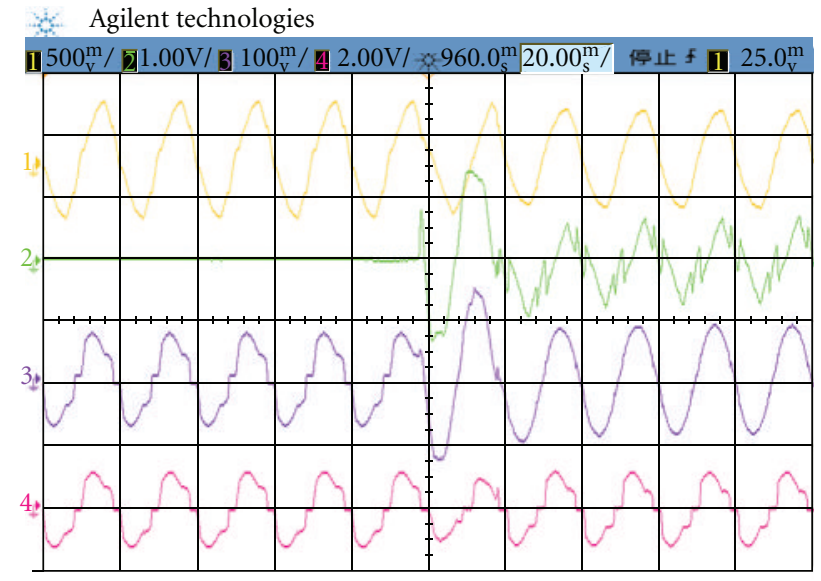

FIGURE 15: The voltage and currents of phase $C$ when SAPF starts running ((1) $300 \mathrm{~V} / \mathrm{div}$, (2) $5 \mathrm{~A} / \mathrm{div}$, (3) $10 \mathrm{~A} / \mathrm{div}$, and (4) $10 \mathrm{~A} / \mathrm{div})$.

that the current tracking control error would be enlarged if the coupling effect was ignored.

A discrete-time mathematical model in the $\alpha-\beta$ domain for the three-phase three-line VSC is derived through orthogonal transform, in which the impact from the neutral point voltage on current tracking control is eliminated. The decoupling of the three-phase currents can be achieved in the $\alpha-\beta$ coordinate system.

Combined with the instantaneous harmonic and reactive currents detection and the PID controller, an integrated decoupled current control scheme has been established. Simulations and experiments have verified the feasibility and effectiveness of the proposed control strategy.

\section{Acknowledgments}

This research work was supported by the National Science Foundation of China (50807033) and the Shandong Provincial Natural Science Foundation (ZR2009FQ025, ZR2009FM013).

\section{References}

[1] M. P. Kazmierkowski and L. Malesani, "Current control techniques for three-phase voltage-source PWM converters: a survey," IEEE Transactions on Industrial Electronics, vol. 45, no. 5, pp. 691-703, 1998.

[2] M. P. Kazmierkowski and M. A. Dzieniakowski, "Review of current regulation methods for VS-PWM inverters," in Proceedings of the IEEE International Symposium on Industrial Electronics, pp. 448-456, Budapest, Hungary, 1993.

[3] S. Buso, L. Malesani, and P. Mattavelli, "Comparison of current control techniques for active filter applications," IEEE Transactions on Industrial Electronics, vol. 45, no. 5, pp. 722729, 1998.

[4] M. A. Rahman, T. S. Radwan, A. M. Osheiba et al., "Analysis of current controllers for voltage-source inverter," IEEE Transactions on Industrial Electronics, vol. 44, no. 4, pp. 477-485, 1997.

[5] R. F. De Camargo and H. Pinheiro, "Comparison of six digital current control techniques for three-phase voltage-fed PWM 
converters connected to the utility grid," in Proceedings of the 36th IEEE Power Electronics Specialists Conference, pp. 14221428, Recife, Brazil, 2005.

[6] N. Yadaiah, N. R. Kumar, and G. T. R. Das, "Comparison of conventional, fuzzy logic and neural based HBPWM current controllers," in Proceedings of the International Joint Conference on Neural Networks 2006, (IJCNN '06), pp. 2986-2992, Vancouver, Canada, July 2006.

[7] E. León Andrés, J. A. Solsona, C. Busada, H. Chiacchiarini, and M. I. Valla, "High-performance control of a three-phase voltage-source converter including feedforward compensation of the estimated load current," Energy Conversion and Management, vol. 50, no. 8, pp. 2000-2008, 2009.

[8] K. R. Padiyar and N. Prabhu, "Analysis of SSR with three-level twelve-pulse VSC-based interline power-flow controller," IEEE Transactions on Power Delivery, vol. 22, no. 3, pp. 1688-1695, 2007.

[9] R. L. Vasquez-Arnez and L. C. Zanetta Jr., "A novel approach for modeling the steady-state VSC-based multiline FACTS controllers and their operational constraints," IEEE Transactions on Power Delivery, vol. 23, no. 1, pp. 457-464, 2008.

[10] L. Xu and V. G. Agelidis, "Flying capacitor multilevel PWM converter based UPFC," IEE Proceedings, vol. 149, no. 4, pp. 304-310, 2002.

[11] Y. Meng, C. Shen, Z. Liu, X. Ji, and Y. Su, "High performance control method with $\mathrm{d}-\mathrm{q}$ axis decoupling and neutral point voltage regulation for three-level NPC voltage-source rectifier," Transactions of China Electrotechnical Society, vol. 22, no. 1, pp. 108-113, 2007.

[12] L. Qu, Z. Yang, Y. Qin, and B. Zhang, "Analysis and design of a decoupling control strategy for three-phase voltagesource PWM converter," Transactions of China Electrotechnical Society, vol. 22, no. 7, pp. 52-57, 2007.

[13] C. Yun and Z. Xiaoming, "A novel active power filter topology based on coordinate transformation," in Proceedings of the 4th IEEE Conference on Industrial Electronics and Applications, (ICIEA '09), pp. 197-200, May 2009.

[14] Z. Xiaoming and Y. Mei, "A novel active power filter based on injection of $\alpha-\beta$ current components to power system," in Proceedings of the 37th IEEE Power Electronics Specialists Conference 2006, (PESC '06), pp. 1-6, June 2006.

[15] D. Tian, P. Jiang, and G. Tang, "Design and implementation of digital filters in active power filter technology," Advanced Technology of Electrical Engineering and Energy, vol. 22, no. 3, pp. 77-80, 2003. 

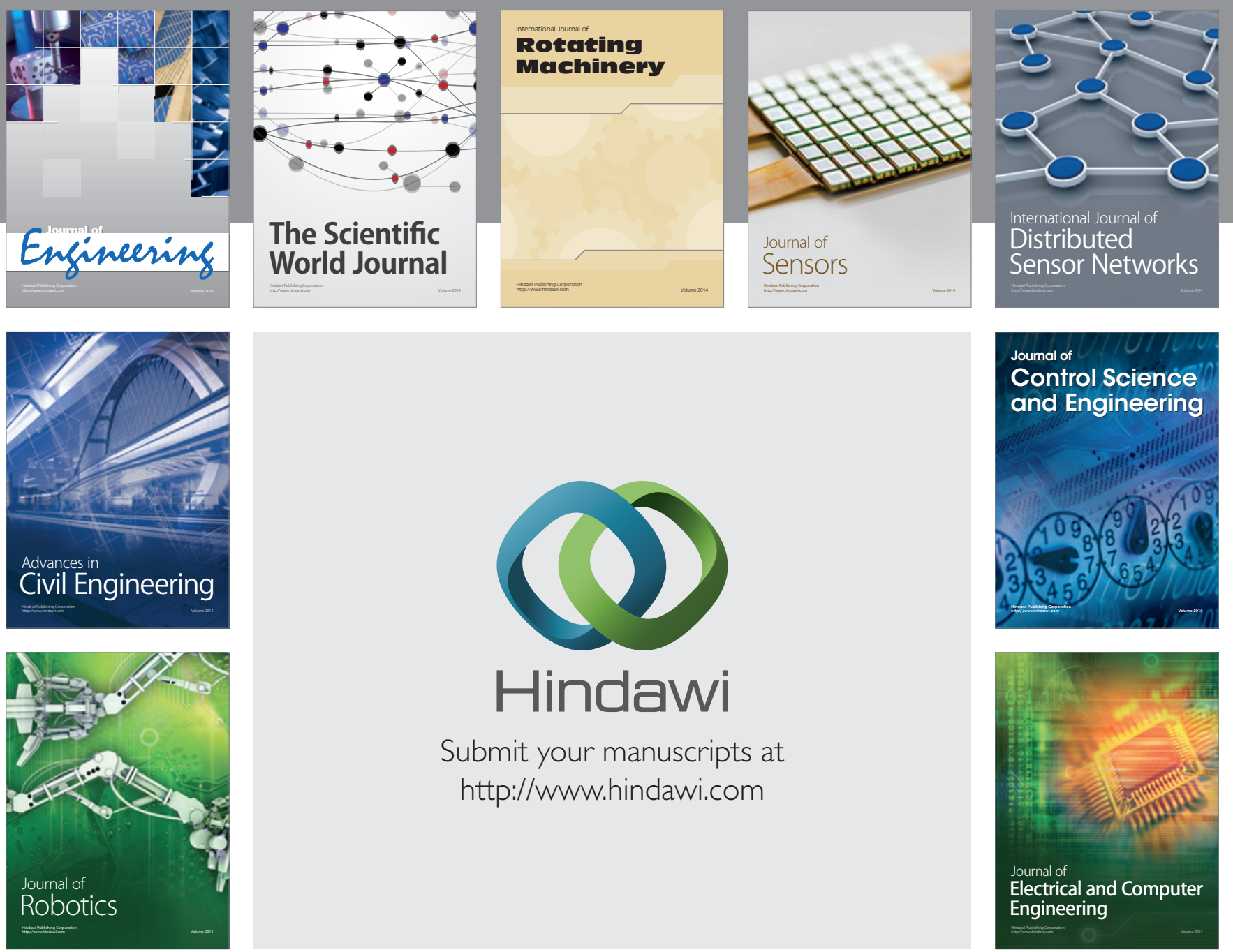

Submit your manuscripts at

http://www.hindawi.com
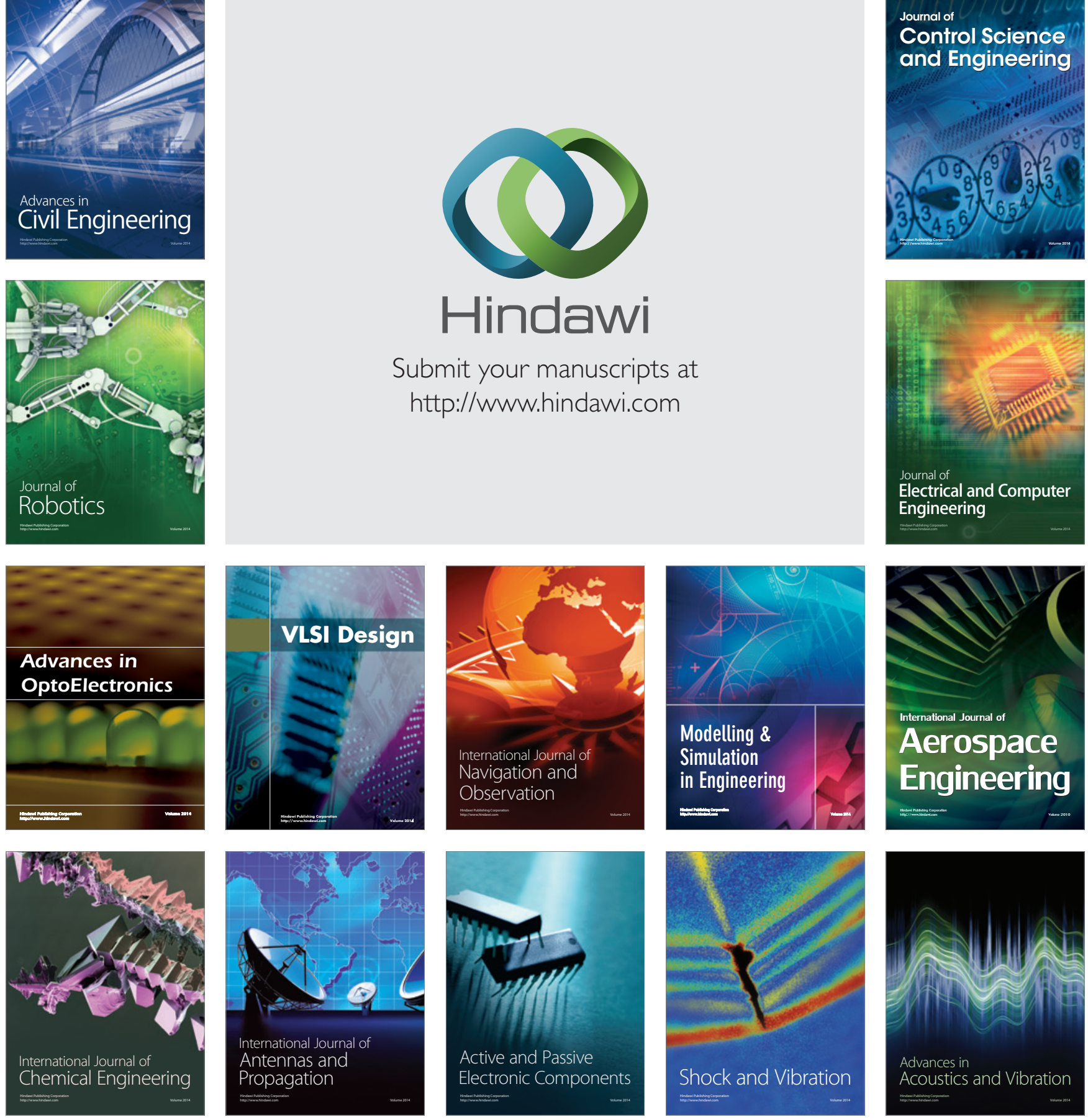